\title{
Partial discharge energy and electrical tree volume degraded in epoxy resin
}

DOI:

10.1109/CEIDP.2015.7352053

Link to publication record in Manchester Research Explorer

\section{Citation for published version (APA):}

Schurch, R., Rowland, S. M., \& Bradley, R. S. (2015). Partial discharge energy and electrical tree volume degraded in epoxy resin. In host publication (pp. 820-823). IEEE. https://doi.org/10.1109/CEIDP.2015.7352053

\section{Published in:}

host publication

\section{Citing this paper}

Please note that where the full-text provided on Manchester Research Explorer is the Author Accepted Manuscript or Proof version this may differ from the final Published version. If citing, it is advised that you check and use the publisher's definitive version.

\section{General rights}

Copyright and moral rights for the publications made accessible in the Research Explorer are retained by the authors and/or other copyright owners and it is a condition of accessing publications that users recognise and abide by the legal requirements associated with these rights.

\section{Takedown policy}

If you believe that this document breaches copyright please refer to the University of Manchester's Takedown Procedures [http://man.ac.uk/04Y6Bo] or contact uml.scholarlycommunications@manchester.ac.uk providing relevant details, so we can investigate your claim.

\section{OPEN ACCESS}


This is the accepted manuscript, which has been accepted by IEEE for publication (C) 2015 . Personal use of this material is permitted. Permission from IEEE must be obtained for all other uses, in any current or future media, including reprinting/republishing this material for advertising or promotional purposes, creating new collective works, for resale or redistribution to servers or lists, or reuse of any copyrighted component of this work in other works. The full reference is:

\title{
'Partial discharge energy and electrical tree volume degraded in epoxy resin'
}

\author{
R. Schurch, S. M. Rowland, and R. S. Bradley \\ IEEE Conference on Electrical Insulation and Dielectric Phenomena, \\ pp. 820-823, 2015
}

DOI: $\underline{10.1109 / C E I D P .2015 .7352053}$ 


\section{Partial discharge energy and electrical tree volume degraded in epoxy resin}

\author{
Roger Schurch \\ Department of Electrical Engineering \\ Universidad Técnica Federico Santa María \\ Valparaíso, Chile \\ roger.schurch@usm.cl
}

\author{
Simon M. Rowland ${ }^{1}$ and Robert S. Bradley ${ }^{2}$ \\ ${ }^{1}$ School of Electrical and Electronic Engineering \\ ${ }^{2}$ School of Materials \\ The University of Manchester \\ Manchester, United Kingdom \\ s.rowland@manchester.ac.uk
}

\begin{abstract}
Electrical trees are hollow artifacts resembling botanical trees generated in high electrical fields, and are a form of polymeric insulation degradation. Most models assume partial discharges, which accompany tree growth, are the cause of material degradation, and so understanding the energy associated with discharges and the energy of vaporization of the material chemical constituents is critical. In this study the volume of trees has been determined through an X-ray Computed Tomography technique, and the energy of discharges by directly measuring PD activity during tree growth. It is shown that approximately $9 \times 10^{5} \mu^{3}$ of material is evaporated per electrical Joule of energy, representing $7 \%$ efficiency in the conversion process.
\end{abstract}

Keywords_partial discharge; PD; electrical tree; degradation

\section{INTRODUCTION}

Electrical trees are one of the main mechanisms of longterm failure in high voltage solid polymeric insulation. Electrical trees are interconnected networks of channels of degradation that grow under partial discharge (PD) activity, and are essentially gas-filled tubules [1]. A vast amount of experiments have been carried out to relate PD activity and tree growth [2]-[7]. Normally, 'phase-resolved PD analysis' (PRPDA) and to a lesser extent, 'pulse sequence analysis' PSA have been used to obtain patterns that characterize tree growth and perhaps identify the general tree morphology or stage of propagation. This approach does not focus on the relation of PD activity and material degradation.

Most of the physical models for tree propagation are based on the concept that the material damage (and consequently tree extension) is originated by the energy dissipated by PDs within the tree [8]. The 'discharge-avalanche model' [9] postulated that the extension of the tree occurs when the accumulated damage in the solid material exceeds a certain materialdependent critical level. The accumulated damage from typically more than $10^{3}$ discharges was required for channel formation. Another model [10], assumed that the damage is proportional to the amount of energy released by the PDs and the channel formation occurs when both the local damage and the local field exceed critical values [11]. In the model proposed in [12], the material damage produced by PDs was determined by the local electrical energy dissipated by the discharges and by the local electrical fields in the dielectric surrounding the tree. The tree would extend when the accumulated damage (quantified as energy) exceeded the energy to form a new channel, which was calculated considering the vaporization energy of the material and the volume of the new segment channel. This concept is described further below.

\section{Partial discharge energy and tree volume degraded}

Given that the tree is composed of hollow channels, it is assumed that the host polymer is vaporized by the action of PDs, breaking all the covalent bonds of the material contained in the equivalent volume of the tree [13]. The fraction of the PD energy that is used in breaking bonds (i.e. the vaporization energy) is a free parameter that in physical models, such as [12], controls the tree propagation rate. In [13] experiments were carried out to compare the PD electrostatic energy supplied at the external terminals and the vaporization energy required to form the tree. The PD measurements for one cycle were taken every 35 cycles of the applied voltage, and from that representative cycle, the PD energy supplied over the entire experiment was determined. The vaporization energy was calculated estimating two parameters: the vaporization energy per unit volume (explained in Section III) and the volume of the resulting tree, estimated from two-dimensional optical images of the tree using the fractal dimension and length of the tree [13]. Using this approach, they reported that $1-5 \%$ of the total electrostatic energy input from the external circuit is used to form tree structures.

A new technical platform has been developed by the authors to analyze electrical trees in three dimensions (3D) [1], [14], [15]. For example, using X-ray Computed Tomography (XCT), which is a high resolution $3 \mathrm{D}$ imaging technique, the tree volume can be measured more accurately. In addition, advances in PD recording technology currently allow continuous recording of PD activity over the entire tree growth experiment. These technologies were deployed in a set of samples and the results reported in this paper.

\section{Methodology}

The influence of the applied voltage on the resulting tree volume was investigated using two samples. The samples were prepared using the conventional point-to-plane configuration with a gap of $\sim 2 \mathrm{~mm}$ between the needle tip and the bottom of 
the sample. The samples consisted of epoxy resin cubes (Huntsman Araldite $\AA$ CY221 - Aradur $\AA$ HY2966, glass transition temperature $25-29^{\circ} \mathrm{C}$ ) of $25 \mathrm{~mm}$ edge with Ogura needles of $3 \mu \mathrm{m}$ tip radius inserted. Two tree growth experiments were carried out, at 10 and $12 \mathrm{kV}$ (sinusoidal $50 \mathrm{~Hz}$ ) respectively, where each sample was stressed for 115 minutes.

The tree growth was monitored by an optical camera and PD measurements over the entire tree growth. Using a balanced circuit arrangement, PDs were detected with the MPD-600 Omicron system, which records the PD events as a series of data including the apparent charge of each discharge and the time, phase angle and instantaneous voltage when each discharge occurred; and separately stores the voltage waveform with a sample every $48 \mu \mathrm{s}$ (sampling rate of $\sim 20 \mathrm{kHz}$ ). The minimum apparent charge to be recorded was set to $2-3 \mathrm{pC}$ to remove the background noise. The stressing time of 115 minutes was counted from the time when the tree initiated, i.e. when a small segment was noticeable by the optical camera and the PD activity started. After the tree growth experiment, the samples were machined to create a $\sim 2 \mathrm{~mm}$ diameter cylinder of polymer containing the tree to be imaged. The samples were imaged using X-ray Computed Tomography (XCT) [1] at the Paul Scherrer Institut, the Swiss Light Synchrotron. A total of 6001 radiographs were taken with $45 \mathrm{~ms}$ of exposure time per radiograph, using an X-ray energy of $16 \mathrm{keV}$. The pixel size was $0.65 \mu \mathrm{m}$ which provided a field of view of $1.6 \mathrm{~mm} \times 1.4 \mathrm{~mm}$ per radiograph. Virtual replicas of the samples were generated from the experiments as explained in [1], [11] and from them, the tree volume (material removed) is readily obtained.

\section{CALCULATION OF PD AND VAPORIZATION ENERGIES}

The PD energy was calculated from the apparent charge, and therefore, corresponds to the energy fed into the terminals of the sample [16]. The expression used was:

$$
\operatorname{PD} \text { Energy }=\sum\left(\mathrm{q}_{\mathrm{i}} \cdot \mathrm{v}_{\mathrm{i}}\right)
$$

where $q_{i}$ is the apparent charge of the discharge and $v_{i}$ is the instantaneous voltage at the terminals of the sample when the discharge occurred, for all ' $\mathrm{i}$ ' PD events. The exact dissipated energy due to PDs at the discharge site is unknown, however the external electrical energy fed into the terminals of the sample is closely related, and thus, it will be used indistinctively here as 'PD energy'.

In epoxy resin, the vaporization energy per unit volume can be estimated using the procedure presented in [12], [13], which is explained as follows. For the calculation, it is assumed that the epoxy resin is made entirely of diglycidyl ether of bisphenol A (DGEBA) molecules with molecular weight of $340 \mathrm{~g}$ and each molecule having 58 covalent bonds with $4 \mathrm{eV}$ of bond energy [12]. Thus, the energy per mole can be estimated as

$$
E_{m o l}=\underbrace{\text { Energy per bond }}_{\text {Energy per molecule }} \overbrace{6.02 \cdot 10^{23}}^{\text {Avogadro's number }}=2.24 \cdot 10^{7} \mathrm{~J}
$$

The density of the epoxy used was $1.15 \mathrm{~g} / \mathrm{cm}^{3}$, giving a molar volume (molar weight divided by density) of $\mathrm{V}_{\mathrm{m}}=$ $2.96 \times 10^{-4} \mathrm{~m}^{3}$. Hence, the energy of vaporization per unit volume $\left(\mathrm{E}_{\mathrm{mol}} / \mathrm{V}_{\mathrm{m}}\right)$ was estimated to be $7.56 \times 10^{10} \mathrm{Jm}^{-3}$. This value multiplied by the tree volume yields the vaporization energy, which was the energy required to degrade the material and form the tree.

\section{RESULTS AND DISCUSSION}

The resulting 3D models (virtual replicas) of the electrical trees contained in the samples are presented in Fig. 1 and parameters characterizing each are summarized in Table 1. From the 3D models, the tree volume was measured and the values are presented in Table 1. As expected, the sample aged at $12 \mathrm{kV}$ has a more bush-type structure than the sample aged at $10 \mathrm{kV}$ and consequently, a greater volume.

PD activity was recorded during tree growth. The magnitude of the apparent charge of the discharges as function of stressing time is depicted in Fig. 2. It should be noted that given that discharges smaller to $2-3 \mathrm{pC}$ were not recorded, the contribution of these discharges to the PD energy is not considered, and an unquantifiable error is included here. However, it is expected that most of the discharges from the tree are above this recording lower limit, considering that this epoxy resin was in a semi-flexible state. Experiments have shown that in epoxy resins, non-conducting trees grow when the epoxy is in its flexible state (above the glass transition temperature) [17], and the magnitude of PDs is in the range 1 $\mathrm{pC}-1 \mathrm{nC}$ with fewer discharges less than 2-3 pC [7], [17].

Considerable differences in the magnitude and trend of the apparent charge are observed between the two samples. Higher values of the discharge rate, and the average energy per discharge were recorded for the sample stressed at $12 \mathrm{kV}$ as shown in Table 1 . This sample had nearly double the number of PDs of the sample aged at $10 \mathrm{kV}$, and despite the voltage being only a $20 \%$ higher, the PD energy of the sample aged at $12 \mathrm{kV}$ was more than five times the energy of PDs from the sample aged at $10 \mathrm{kV}$, evidencing the higher amplitude of PDs in the sample aged at $12 \mathrm{kV}$. One minute (the $65^{\text {th }}$ ) was selected to construct and compare the PRPD plots, which are shown in Fig. 3. The apparent charge was plotted in logarithmic scale and unipolar (the polarity of the discharge was disregarded). For the equivalent stressing time (the $65^{\text {th }}$ minute), similar PD patterns were obtained, however, considerable differences in the magnitude and repetition rate in the discharges are observed.

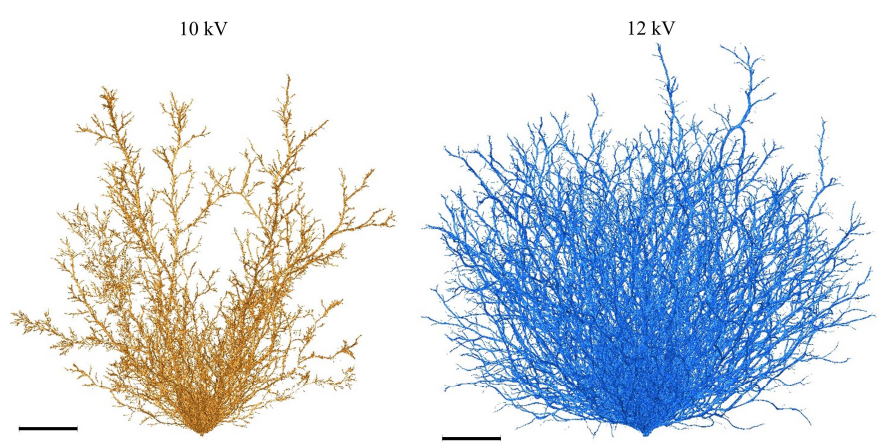

Fig. 1. 3D renderings of samples aged at $10 \mathrm{kV}$ and $12 \mathrm{kV}$. Scale bar: $200 \mu \mathrm{m}$. 
The tree volume of each sample was measured from the virtual replicas and presented in Table 1. However, there is naturally some uncertainty in the generation of the tree replicas which affects the accuracy of the result. One of the factors that affected the accuracy concern problems in the reconstruction process that generated artefacts around some tree channels. These artefacts were associated to the selection of the center of rotation in the reconstruction [1], [11], that produced shadows and artificial channel borders in some of the tree channels located in the upper part of the tree. Another factor was the possibility of having tree channels that are not hollow tubes but low density material. During the image segmentation process, these factors can be partially corrected manually. Nevertheless, it is estimated that the impact in the accuracy in the volume measurement is less than $15 \%$. In addition, a small part of the sample aged at $12 \mathrm{kV}$ was out of the field of view and thus, that volume could not be included in the calculation. However, from the optical images and the suggested progression of the channels, this lost volume was considered negligible $(\sim 1 \%)$.

Using an energy of vaporization per unit volume of $7.56 \times 10^{10} \mathrm{Jm}^{-3}$ (see Section III), the vaporization energy associated to the tree volume of each sample is calculated and presented in Table 1. Finally, the ratio between the vaporization energy which was required to form the tree and the PD energy could be determined. The ratio was around $7 \%$ and it is higher than the value reported in [13], which was in the range of $1-5 \%$. The difference may arise from the fact that in [13] the PD energy and the volume of the tree were estimated (see Section I). Equivalently, the volume per PD energy unit could be emphasized, which gives a more direct relationship between the material degraded and the energy released by the PDs. These parameters are important for most of the tree modeling methodologies that uses a physical approach, in which the volume degraded is proportional to the energy released by the PDs.

The result obtained shows that, for the cases presented here, only around $7 \%$ of the PD energy supplied at the external terminals was required to form the tree. The remaining energy $(\sim 93 \%)$, as suggested in [13], could have been dissipated as heat, light and mechanical energy.

\section{CONCLUSIONS}

This paper has presented the results of experiments that related the external electrical energy fed into the terminals of a sample during PD activity and the tree volume degraded. PDs were recorded during the entire experiment and the tree volume was measured from the 3D virtual replica generated from XCT experiments.

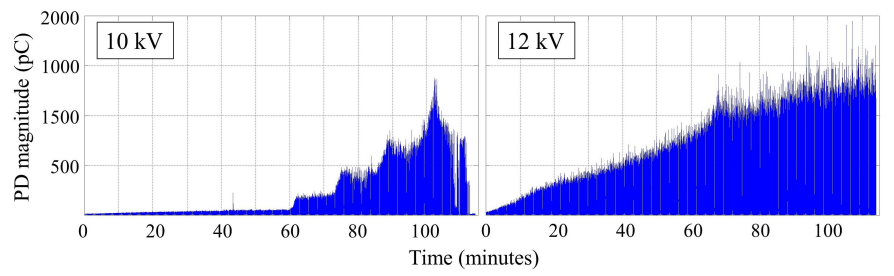

Fig. 2. Magnitude of the apparent charge $\mathrm{Q}(\mathrm{pC})$ during the tree growth.
Table 1. PD activity, tree volume and vaporization energy.

\begin{tabular}{|l|c|c|}
\hline \multicolumn{1}{|r|}{ Sample } & $\mathbf{1 0} \mathbf{~ k V}$ & $\mathbf{1 2 ~ k V}$ \\
\hline \hline Time PDs (min) & 115 & 115 \\
\hline Number of PDs & $4.8 \times 10^{6}$ & $9.1 \times 10^{6}$ \\
\hline Discharge rate (\#PD/s) & 705 & 1324 \\
\hline Discharge rate (\#PD/cycle) & 14.1 & 21.7 \\
\hline PD energy $(\mathbf{J})$ & $\mathbf{1 . 6 5}$ & $\mathbf{9 . 1 2}$ \\
\hline Energy per discharge $(\mathrm{J})$ & $3.4 \times 10^{-7}$ & $1.0 \times 10^{-6}$ \\
\hline \hline Tree length $(\mathrm{mm})^{(*)}$ & 1.23 & 1.34 \\
\hline Volume tree $\left(\mathbf{~ m m}^{3}\right)$ & $\mathbf{1 . 6 \times 1 0 ^ { \mathbf { 6 } }}$ & $\mathbf{8 . 1 \times 1 0 ^ { 6 }}$ \\
\hline Volume per discharge $\left(\mu \mathrm{m}^{3}\right)$ & 0.3 & 0.9 \\
\hline Vol. per energy unit $\left(\mu \mathrm{m}^{3} / \mathrm{J}\right)$ & $9.7 \times 10^{5}$ & $8.9 \times 10^{5}$ \\
\hline \hline Vapor. Energy $(\mathbf{J})$ & $\mathbf{0 . 1 2}$ & $\mathbf{0 . 6 1}$ \\
\hline Vapor./PD Energy ratio & $7.4 \%$ & $6.7 \%$ \\
\hline
\end{tabular}

${ }^{(*)}$ Tree extent in the needle direction, calculated multiplying the number of slices used to generate the virtual replica of the tree by the pixel size (separation between the slices).

The vaporization energy, determined by the adding of the chemical bond energies, which is the energy required to dissociate the atoms from the material previously within the tree channels, was around $7 \%$ of the PD energy at the external terminals. Approximately $9 \times 10^{5} \mu \mathrm{m}^{3}$ of material is evaporated per electrical Joule of energy. This value can be used in the physical models of tree growth to relate PD energy and material damage and thus, to control the simulated tree growth rate.

\section{ACKNOWLEDGMENT}

The authors thank Anne Bonnin at Paul Scherrer Institut (Swiss Light Synchrotron) for her assistance in the XCT experiments. Roger Schurch would like to thank Jose Millan for his help in generating virtual replicas.

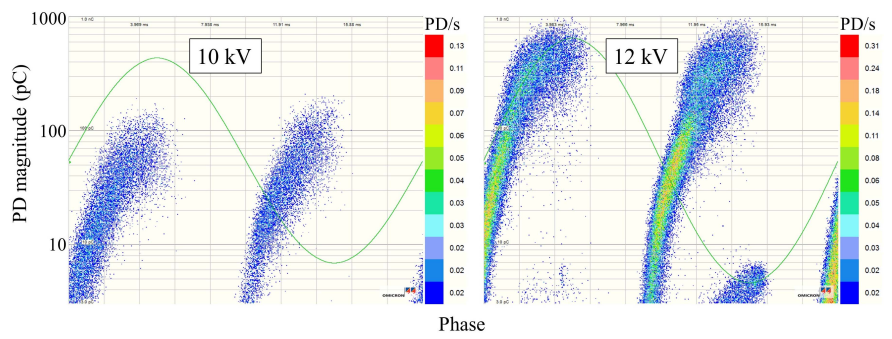

Fig. 3. PRPD plots - Logarithmic scale, unipolar amplitude. 


\section{REFERENCES}

[1] R. Schurch, S. M. Rowland, R. S. Bradley, and P. J. Withers, "Imaging and analysis techniques for electrical trees using X-ray computed tomography," IEEE Trans. Dielectr. Electr. Insul., vol. 21, no. 1, pp. 53-63, 2014.

[2] J. V Champion, S. J. Dodd, and J. M. Alison, "The correlation between the partial discharge behaviour and the spatial and temporal development of electrical trees grown in an epoxy resin," J. Phys. D. Appl. Phys., vol. 29, no. 10, p. 2689, 1996.

[3] Suwarno and et al., "Partial discharges due to electrical treeing in polymers: phase-resolved and time-sequence observation and analysis," J. Phys. D. Appl. Phys., vol. 29, no. 11, p. 2922, 1996.

[4] M. D. Noskov, M. Sack, A. S. Malinovski, and A. J. Schwab, "Measurement and simulation of electrical tree growth and partial discharge activity in epoxy resin," J. Phys. D. Appl. Phys., vol. 34, no. 9, p. 1389, 2001.

[5] F. Guastavino and B. Cerutti, "Tree growth monitoring by means of digital partial discharge measurements," IEEE Trans. Dielectr. Electr. Insul., vol. 10, no. 1, pp. 65-72, 2003.

[6] R. Vogelsang, B. Fruth, T. Farr, and K. Fröhlich, "Detection of electrical tree propagation by partial discharge measurements," Eur. Trans. Electr. Power, vol. 15, pp. 271-284, 2005.

[7] S. J. Dodd, N. M. Chalashkanov, and J. C. Fothergill, "Partial discharge patterns in conducting and non-conducting electrical trees," in IEEE Int'l. Conf. Solid Dielectr. (ICSD), pp. 1-4, 2010.

[8] A. S. Vaughan, I. L. Hosier, S. J. Dodd, and S. J. Sutton, "On the structure and chemistry of electrical trees in polyethylene," J. Phys. D. Appl. Phys., vol. 39, no. 5, p. 962, 2006.
[9] L. A. Dissado and P. J. J. Sweeney, "Physical model for breakdown structures in solid dielectrics," Phys. Rev. B, vol. 48, no. 22, pp. 1626116268,1993

[10] M. D. Noskov, A. S. Malinovski, M. Sack, and A. J. Schwab, "Selfconsistent modeling of electrical tree propagation and PD activity," IEEE Trans. Dielectr. Electr. Insul., vol. 7, no. 6, pp. 725-733, 2000.

[11] R. Schurch, "Three-Dimensional Imaging and Analysis of Electrical Trees," PhD Thesis, The University of Manchester, Manchester, UK, 2014.

[12] S. J. Dodd, "A deterministic model for the growth of non-conducting electrical tree structures," J. Phys. D. Appl. Phys., vol. 36, no. 2, pp. 129-141, 2003.

[13] M. A. Brown, J. V Champion, S. J. Dodd, and P. Mudge, "An investigation of partial discharge energy dissipation and electrical tree growth in an epoxy resin," in IEEE Int'l. Conf. Solid Dielectr. (ICSD), pp. 288-291, 2004

[14] R. Schurch, S. M. Rowland, R. S. Bradley, and P. J. Withers, "Comparison and Combination of Imaging Techniques for Three Dimensional Analysis of Electrical Trees," IEEE Trans. Dielectr. Electr. Insul., vol. 22, pp. 709-719, 2015.

[15] S. M. Rowland, R. Schurch, M. Pattouras, and Q. Li, "Application of FEA to image-based models of electrical trees with uniform conductivity," IEEE Trans. Dielectr. Electr. Insul., vol. 22, pp. 15371546, 2015.

[16] IEC 60270:2000, "High-voltage test techniques - Partial discharge measurements," (Standard), 2000.

[17] J. V Champion and S. J. Dodd, "Simulation of partial discharges in conducting and non-conducting electrical tree structures," J. Phys. D. Appl. Phys., vol. 34, no. 8, p. 1235, 2001. 